\title{
Entrepreneurship Team Research: Theoretical Framework and Future Prospects
}

\author{
Qiuxia Lu ${ }^{1, a}$, Hui Tian ${ }^{1, b, *}$ \\ ${ }^{1}$ School of Economics \& Management, Nanjing University of Science \& Technology, Nanjing 210094, \\ China \\ a694748599@qq.com, b1502094737@qq.com \\ *corresponding author
}

Keywords: Entrepreneurial team, Theoretical framework, Future prospects

\begin{abstract}
As the main form of entrepreneurship, the entrepreneurial team is attracting more and more attention from the society. There are many researches on the theory of entrepreneurial team in China, but the research topic is relatively scattered and lacks rigorous and in-depth empirical research. Based on the theory of "structure-conduct-performance" in industrial economics, this paper proposes an integrated theoretical framework, and according to the existing research, the author reviews and summarizes the contents of the three parts of the framework and analyzes the shortcomings and limitations. Finally, we propose the direction of future entrepreneurship team research in the localization environment of China.
\end{abstract}

\section{Introduction}

The concept of entrepreneurial teams originated in 1975, when Timmons's "entrepreneurial team is America's dream or nightmare" published in the American journal of small business management $^{[1]}$. In recent years, scholars at home and abroad have done a lot of research on the entrepreneurial team, but different scholars have diversified their research themes and focuses. Therefore, it is of great theoretical and practical significance to carry out the necessary collation of existing literature and to further study the entrepreneurial team. This article is based on the "structure - conduct - performance" (SCP) model in the field of industrial economics research, it integrates the mainstream view of entrepreneurial teams on the current, and put forward a systematic and in-depth theoretical framework. The SCP theory holds that the industrial structure determines the state of competition in the industry and determines the behavior and strategy of the enterprise, thus ultimately determining the performance of the enterprise ${ }^{[2]}$. Although SCP is a theory in the field of industrial economics, its research on the industrial structure and the relation to the internal behavior of industries also applies to team structure and behavior, which has been tested by a large number of theoretical and empirical research. Therefore, this article will use it as a basis for building entrepreneurial team research theoretical framework. In accordance with the SCP theoretical paradigm to classify the relationship between its research topics and variables, we propose an integrated theoretical framework for the study of entrepreneurial teams. (As shown in Figure 1)

As the main body of entrepreneurial activity, the internal structure of entrepreneurial team includes the statistical characteristics of team members, heterogeneity and social network of team members. These structural variables have significant influence on the outcome variables of entrepreneurial team's performance and enterprise's healthy growth. At the same time, the formation of the entrepreneurial team is not the accumulation of a single entrepreneur but the "1 $+1>2$ " synergistic development process, which has many differences in behavior compared with the entrepreneurial individuals. Mainly reflected in the leadership behavior, conflict behavior, team learning behavior and so on. 


\begin{tabular}{|c|c|c|}
\hline Structure & Conduct & Perfance \\
\hline 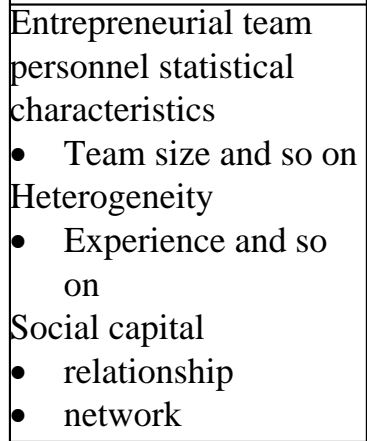 & \begin{tabular}{|ll} 
Team management \\
- \\
Team learning \\
- Innovative thinking \\
Information sharing \\
and so on \\
Team conflict \\
- Cognition \\
Emotions and so on
\end{tabular} & $\begin{array}{ll}\text { Growth performance } \\
\text { - } & \text { Sales growth } \\
\text { - } & \text { Profit rate } \\
\text { number of } \\
\text { employees } \\
\text { Financing ability } \\
\text { - } & \text { Get risk funding } \\
\text { - } & \text { IPO }\end{array}$ \\
\hline
\end{tabular}

Fig. 1 The integrated framework of Entrepreneurship team research

Note: The contents of this framework are based on the prevailing research literature concluded that the actual situation is not limited to the above.

\section{Review of Structural Variables}

\subsection{Entrepreneurial team's personnel statistical characteristics}

The Entrepreneurial team personnel statistical characteristics reflect the structural characteristics of entrepreneurial team, including the team size, the average age of the team and the average level of education of the team and so on.

In the current literature, the size of the entrepreneurial team is often examined as a control variable rather than as an independent variable to examine its effect on the outcome variable. Some scholars found that if the team is too large, it will easily lead to inconsistencies within the team, resulting in conflict behavior and ambiguous work definition, it will have a negative impact on the establishment of team members and team building. But at the same time, some scholars pointed out that team size makes the team have many unparalleled advantages, such as more access to the resources needed, a richer source of information and a stronger ability to carry out work in parallel. Empirical studies by Cooper et al. (1994) show that the size of the startup team is positively related to the startup's sales and staff numbers.

The average age of start-up team has been one of the variables studied by many scholars. One of the intuitive reasons is that it is related to team members' work experience, previous experience and ability of members. Existing research findings seem to be more inclined to the young entrepreneurial team. Wiersema and Bentel (1992) pointed out that although the aged entrepreneurial team represents a relatively wealthier member experience, they are also relatively more likely to be dogmatic and stubbornly risky ${ }^{[3]}$. While younger start-ups, less experienced, are more entrepreneurial and risk-taking for substantial profits and market share.

The average education level of the entrepreneurial team generally contributes to good entrepreneurial performance. A higher level of education means the optimization of the structure of the entrepreneurial team members. Colombo and Grilli (2005) examined the impact of the average level of education of start-up teams on the growth of employees and the access to venture capital. The results show that: the higher the education level of team members, the more benefit the employee scale growth and the venture capital investment. Compared with the entrepreneurial team with more professional education background, the entrepreneurial team with more education in science and technology has more significant impact on employee growth ${ }^{[4]}$.

\subsection{Entrepreneurial team's heterogeneity}

If the demographic characteristics reflect the general human capital level of the entrepreneurial team, then the heterogeneity reflects the unique human capital level of the entrepreneurial team, that 
is, the qualitative side. Katzenbach and Smith (1993) point out that the heterogeneity of entrepreneurial teams is a group of individuals, whose characteristics, skills and thoughts are different and that can affect the team's goals and performance ${ }^{[5]}$.

According to the view of resource-based view, the higher the degree of heterogeneity of the entrepreneurial team, the more they tend to have diversified knowledge and skills, so as to have more resources and stronger capabilities, which is conducive to improving entrepreneurial performance. However, empirical research shows that the impact of heterogeneous entrepreneurial teams on entrepreneurial performance is both positive and negative or irrelevant. This is because, although heterogeneous entrepreneurship groups can improve entrepreneurial performance through enrichment of cognition, their internal counterparts are also more prone to antagonism and conflict, thus undermining their entrepreneurial performance. Two empirical comparative studies between Ensley and Hmieleski in 2005 and 2007 attest to this view.

The heterogeneity of the empirical background is more concerned by scholars, because it largely results in the difference of the level of human capital and social network capital of different entrepreneurial teams ${ }^{[6]}$. Whether the level of heterogeneity is high or low is more favorable to entrepreneurial performance, there is no clear answer so far and we need to examine specific situations. Under different circumstances, Hmieleski and Ensley (2007) pointed out that in the authorization type leadership style of entrepreneurial teams, members are more conducive to achieve good performance if their experience more homogenized, and in the hereditary members of the leadership style of entrepreneurial teams, members are more conducive to achieve good performance if their experience more heterogeneity.

\subsection{Entrepreneurial team's social capital}

The entrepreneurial team's social capital comes from the interpersonal networks, social relationships and embedded structures of team members that shape the collective perception of the team and help the entrepreneurial team find and identify business opportunities and put them into practice $^{[7]}$. Research shows that having a broad business relationship with the outside world is important to discovering entrepreneurial opportunities as the large-scale networks can generate rawer, unprocessed information, which is what makes a great entrepreneur more likely to identify opportunities and create conditions than others. In addition, strong ties to the entrepreneurial team's social network, especially with family and friends, are also becoming more and more important as business plans start to take hold. During this period, an exact and stable network of contacts provided an endless stream of support and protection for the money and manpower needed to start a business, which is why smallest, medium and new start-ups are family-owned.

\section{Review of mediate Variables}

In the research of entrepreneurial team's SCP theoretical framework, the mediate variables represent entrepreneurial team's behavior based on the entrepreneurial team structure.

\subsection{Entrepreneurial team's management}

In mature businesses, the organizational structure, systems and processes used to guide employee behavior are structured. However, in startups these organizational elements are either incomplete or incomplete, and employee behavior is strongly influenced by the leadership style of the founder or entrepreneurial team. So, choosing the right leadership style for a startup team will help manage the startup team. Existing research distinguishes the effects of two different types of entrepreneurial teams, empowerment-style leadership and authoritative leadership, as well as transformational leadership and transactional leadership. Authorized leadership is conducive to inspire subordinate potential and intrinsic motivation, thus showing independent behavior, self-management, participation in decision-making, good thinking and other behavioral patterns. In the entrepreneurial context, these positive behaviors can help start-ups compete with their incumbent enterprises that have the resources advantage. But we can't conclude that the authoritative leadership must not be suitable for the entrepreneurial team, If the subordinates' ideas and behaviors are not consistent, it is 
very difficult to form a unified action to achieve the established goals, especially when the entrepreneurial team has a high degree of heterogeneity and a volatile external environment. The authoritative leadership just can play an active role in this situation.

Transformational leadership is committed to forming a common vision to inspire subordinates' self-efficacy and idealism, while transactional leadership focuses on the use of material incentives and rational incentives for subordinates. In fact, the role of entrepreneurial team leadership style is very complex, and Ensley et al. (2006) conducted an in-depth study. They found that without considering other factors, authoritative leadership and transactional leadership are positively correlated with entrepreneurial performance, while authorized leadership and transformational leadership are negatively correlated with entrepreneurial performance. And once the variable of environmental turbulence is added, the effect of empowerment and transformational leadership on entrepreneurial performance is not only negative, but also more obvious than authoritative and transactional leadership.

\subsection{Entrepreneurship team learning}

Entrepreneurial team learning is the rise of research in 2009, for what is the entrepreneurial team learning, the current academic is not yet clearly defined. Chandler \& Lyon (2009) argue that entrepreneurial team learning is the process of acquiring entrepreneurial team knowledge through natural learning, observational learning, and finding-attention learning and grafting learning ${ }^{[8]}$. The Entrepreneurship Team keeps its innovative vitality and enhances its core competitiveness through continuous learning, fully integrating the individual strengths of its members, constantly identifying and resolving problems, enhancing its overall ability to acquire and utilize resources and its adaptability to the entrepreneurial environment.

Lee and others analyzed the relationship between entrepreneurial team learning and entrepreneurial team performance through empirical research on 125 entrepreneurial teams, and found that entrepreneurial teams can improve the entrepreneurial team's performance by learning to improve the entrepreneurial team's competencies.

Through continuous exchange of information within the entrepreneurial team, the entrepreneurial team reflect on the experience and learning in the entrepreneurial process, and this is beneficial to the development of enterprises.

\subsection{Entrepreneurial team's conflict}

As the organizational structure and rules and regulations of start-ups are not yet mature and stable, there may be disagreements and Cognitive inconsistencies among the members of the entrepreneurial team, the entrepreneurial team and other stakeholders, which lead to conflicts. Ensley and Pearce (2001) define conflict as a process by which teams can make decisions, take actions, and build common visions ${ }^{[9]}$.

On the Impact of Conflict on Entrepreneurial Performance, Higashide and Birley (2002) examine the relationship between entrepreneurial teams and venture capitalists in conflict and firm performance. They add two new types of conflicts based on cognitive and emotional conflicts - the goal conflict and the policy conflict. The former reflects the differences in objectives between the two sides, the latter reflects the differences between the two sides on the implementation of the policy. The empirical results show that the affective conflicts are negatively correlated with the firm's performance, while the cognitive conflicts are positively correlated with the firm's performance. Furthermore, compared with the policy conflicts, the goal conflict further strengthens the relationship between the emotional conflicts and the cognitive conflicts and the firm's performance. Ensley and Pearce (2001) explored the effects of conflict behavior among venture business team members. They also found that cognitive conflicts are positively related to performance indicators such as profit, sales and growth, while emotional conflicts are all negatively related to them ${ }^{[10]}$. 


\section{Review of outcome variables}

At present, most of the research on entrepreneurial performance is based on the performance theory of strategic management and organizational management. March and Simon (1998) argue that the theory applied frequently in the current research on entrepreneurial performance is stakeholder theory, and that there is a multi-dimensional index on the key entrepreneurial performance focused by entrepreneurs. These indicators are not fixed.

Financial indicators are the most widely used entrepreneurial performance dimensions of scholars, including the return on assets, cash flow, profit indicators and so on. However, the financial indicators can only reflect part of the characteristics of entrepreneurial performance, for the average mature enterprises, the index is mostly used as the performance evaluation standard. While, for the start-up enterprises, the financial indicators can't reflect the entrepreneurial effects and characteristics of the entrepreneurial activities that are different from the general mature enterprises. Therefore, the measurement of performance using the single financial performance dimension is not comprehensive and inaccurate. Chavarthy (1986) suggests that due to the difficulty of measuring entrepreneurial performance and the poor availability of relevant data, several dimensions may be considered for measuring entrepreneurial performance.

However, none of the above performance indicators reflect the fact that the entrepreneurial team or a single entrepreneur often has to seek the help of venture capitalists from the outside due to the lack of sufficient self-owned investment and realize an IPO as soon as possible, in order to get enough cash flow. This is indeed the key to the success of entrepreneurship and must be reflected in the connotation of its performance. To this end, Beckman increased the introduction of venture capital and IPO to reflect the performance of this key link in the performance indicators to examine the entrepreneurial team's ability to finance.

\section{Limitations}

At present, most of the research on entrepreneurial team's structural variables in entrepreneurial team literature research is based on the original manifestations of variables such as team size, age and educational background, and some of them overlap. Therefore, it is unreasonable to study the influence of these elements separately on the performance of the entrepreneurial team. In addition, the current entrepreneurial team research is basically examining the impact of a structural variable, the lack of these variables together to make a comprehensive consideration. We also need to look at the entrepreneurial team's behavior and processes from a power perspective because the power allocation among the entrepreneurial team members affects their leadership, change, decision-making, and conflicts. Scholars have used multiple indicators of the entrepreneurial team's measurement of outcomes, all without exception, at the enterprise level to reflect their entrepreneurial performance, lack of team and individual level. There is the current study of the outcome variables too focused on the economy, ignoring the entrepreneurial team behavior main body - people's unique social and emotional goals.

\section{Future research topics and directions}

First of all, as far as the whole theoretical framework is concerned, there is not yet a single empirical study that systematically and comprehensively tests the variables listed in the framework and the relationships among them. The theoretical framework is more based on the integration of existing research results. So, in order to construct the theoretical system of entrepreneurial team based on it and its core, the reliability and validity must be reliably guaranteed. This requires future research from the theoretical and empirical two aspects of the theoretical framework of the full connotation and the strength of its interpretation to fully justify.

Second, the existing research on entrepreneurial team considers more about entrepreneurial behavior and the process itself, while less concerned about the impact of the external environment. In fact, the entrepreneurial team's behavior and processes are largely matched by the external 
network environment. The political environment is another situational factor that influences the team's entrepreneurial process, especially in the socialist environment of our country and the market economy. Therefore, the related researches in the future can also extensively examine and compare the differences in the behaviors and processes of the entrepreneurial teams in different situations, and provide guidance and reference for creating a social environment conducive to (teamwork) entrepreneurship.

\section{References}

[1] TIMMONS J A. THE ENTREPRENEURIAL TEAM: AN AMERICAN DREAM OR NIGHTMARE? [J]. 1975.

[2] FERGUSON P R, FERGUSON G J. The Structure-Conduct-Performance Paradigm [M]. Macmillan Education UK, 1994.

[3] WIERSEMA M F, BANTEL K A. Top Management Team Demography and Corporate Strategic Change, F, 1992 [C].

[4] COLOMBO M G, GRILLI L. Founders' human capital and the growth of new technology-based firms: A competence-based view [J]. Research Policy, 2005, 34(6): 795-816.

[5] JR K, DK S. The discipline of teams [J]. Harvard business review, 1993, 71(2): 111.

[6] KLOTZ A C, HMIELESKI K M, BRADLEY B H, et al. New venture teams: a review of the literature and roadmap for future research [J]. Journal of Management, 2014, 40(1): 226-55.

[7] BARON R A, TANG J. Entrepreneurs' Social Skills and New Venture Performance: Mediating Mechanisms and Cultural Generality [J]. Journal of Management, 2008, 35(2): 282-306.

[8] CHANDLER G N, LYON D W. Involvement in Knowledge-Acquisition Activities by Venture Team Members and Venture Performance [J]. Entrepreneurship Theory and Practice, 2009, 33(3): 571-92.

[9] ENSLEY M D, PEARCE C L. Shared Cognition in Top Management Teams: Implications for New Venture Performance [J]. Journal of Organizational Behavior, 2001, 22(2): 145-60.

[10] OLSON B J, PARAYITAM S, BAO Y. Strategic Decision Making: The Effects of Cognitive Diversity, Conflict, and Trust on Decision Outcomes [J]. Journal of Management Official Journal of the Southern Management Association, 2007, 33(2): 196-222. 